\title{
DETERIORATIVE EFFECT OF SULPHUR DIOXIDE UPON PAPER IN AN ATMOSPHERE OF CONSTANT HUMIDITY AND TEMPERATURE ${ }^{1}$
}

\author{
By Arthur E. Kimberly ${ }^{2}$
}

\section{ABSTRACT}

A preliminary survey of the causes of the deterioration of record papers in libraries having indicated atmospheric sulphur dioxide as an important factor in the deterioration, 14 different commercial book and writing papers were exposed for 240 hours to air containing 2 to 9 parts of sulphur dioxide per 1,000,000 parts of air. The temperature and relative humidity were kept constant at $30^{\circ}$ C. and 65 per cent. Upon determining the physical and chemical characteristics of the selected papers after this treatment, the following effects were observed: A marked loss of folding endurance, accompanied by little change in tensile breaking strength, was observed. The total acidity and copper number increased considerably, while relatively little change in alpha cellulose content was observed, thus indicating that the modified forms of cellulose present in the original substance were the main points of attack. Iuitial quality was apparently no criterion of resistance to sulphur dioxide, since some of the low-grade papers unsuitable for permanent record use, as determined by the usual tests, suffered less from exposure to this gas than did high-grade papers. These facts add to the evidence in favor of the modification of library ventilating systems so as to eliminate acid pollution.

\section{CONTENTS}

I. Introduction

II. Description of apparatus

III. Description of papers used

IV. Description of test methods

V. Procedure

VI. Results _.

VII. Discussion of results

VIII. Summary

IX. Acknowledgment. 171

\section{INTRODUCTION}

The injurious effect of smoke upon vegetation ${ }^{3}$ and building materials ${ }^{4}$ in industrial localities has been well recognized for some time, as has the deleterious action of the sulphur dioxide present in the fumes emanating from certain types of smelters. ${ }^{56}$ In recent years atmospheric pollution has become of increasing concern to the inhabitants of cities, and many investigations have been conducted

1 This is one of a series of investigations concerning the preservation of written and printed records which are being made at the Bureau of Standards with the assistance of a fund granted for the purpose by the Car-

2 Research associate, National Research Council.

8 The Effect of Smoke on Vegetation, Mellon Institute Smoke Bulletin No. 7.

The effect of Smoke on Building Materials, Mellon Institute Smoke Bulletin No. 6.

- Report of the Selby Smelter Commission, U. S. Bureau of Mines, Bulletin No.98.

Haywood, J. K., J. A. Am. Chem. Soc., vol. 29, p. 998. 
to determine the extent of the nuisance as well as means of abating it. $^{789101112}$ A study of statistics from 15 American and European cities showed air pollutions ranging from 0.2 to 3.0 parts of sulphur dioxide per 1,000,000 parts of air and an annual precipitation of sulphuric acid averaging from 11 to 190 tons per square mile. A further discussion of this problem has been given in a previous paper. ${ }^{13}$ Additional evidence of the increasing pollution of modern urban atmospheres is given by a recent investigation by the Bureau of Standards of the causes of "winter damage" or the rotting of damp cotton fabric upon exposure to outside air experienced by laundries throughout New England. ${ }^{14}$ Atmospheric sulphur dioxide, which is oxidized on the fabric to sulphuric acid, was found to be the cause of the phenomenon. The action is accelerated by the presence of minute quantities of iron or of chlorine bleaching residues.

Despite the great amount of evidence at hand to show the increase in the acidic nature of modern atmospheres but one attempt to determine the effect of sulphur dioxide upon paper has been found described in the literature. This work, by Richter, ${ }^{15}$ involved the exposure of representative papers to the action of air-sulphur dioxide mixtures containing 1,2 , and 5 per cent sulphur dioxide, respectively, for periods up to 240 hours. The change of folding endurance incident to this exposure was then determined. In the concentrations of sulphur dioxide used, the decrease in folding endurance was found to be of considerable magnitude for each of the various types of paper tested. Exposures to 5 per cent sulphur dioxide for 240 hours resulted in decreases in folding endurance ranging from 48 to 68 per cent. All of these experiments were carried out in an atmosphere saturated with moisture at $20^{\circ} \mathrm{C}$. $\left(68^{\circ} \mathrm{F}\right.$.).

Although the work of Richter shows conclusively that relatively high concentrations of sulphur dioxide acting upon paper in a watersaturated atmosphere produce a large decrease in folding endurance, it seemed desirable to obtain further information of the effect of concentrations more nearly approaching those likely to be present in libraries. Therefore a series of commercial book and writing papers of various fiber compositions were exposed to the action of a sulphurdioxide air mixture, in which the sulphur-dioxide content was maintained at 2 to 9 parts of sulphur dioxide per 1,000,000 parts of air, the exposure taking place at $30^{\circ} \mathrm{C} .\left(86^{\circ} \mathrm{F}\right.$.) and 65 per cent relative humidity for 240 hours. The concentration of sulphur dioxide used was the closest to actual conditions that could be accurately maintained with the equipment at hand. An elevated temperature was needed in order to produce a definite effect in a short time, so $30^{\circ} \mathrm{C}$. $\left(86^{\circ} \mathrm{F}\right.$.) was chosen. This temperature and the humidity used $(65$ per cent relative humidity) are representative of average summer conditions in the United States as determined by the United States Weather Bureau.

7 Smoke abatement, Report of Committee of Chicago Chamber of Commerce; 1915.

8 Recent Progress in Smoke Abatement in Manchester, Mellon Institute Smoke Bulletin No. 10.

$\checkmark$ Meller, H. B., Mech. Engr., vol. 48, pp. 11a, 1275; 1926.

10 Burrell, B. A., Proc. Leeds Phil. and Lit. Soc., Sci. Sec., vol. 1, pt. 3, p. 116; 1926.

11 Monnett, Osborne, U. S. Bureau of Mines Technical Paper No. 273.

12 Monnett, Parrott, and Clark, U. S. Bureau of Mines Bulletin No. 254.

13 Kimberly, A. E., and Hicks. J. F. G., A Survey of Storage Conditions in Libraries Relative to the Preservation of Records, B. S. Misc. Pub. No. 128.

${ }_{14}$ Laundry "Winter Damage," Wilkie, John B., B. S. Jour. Research, vol. 6, p. 593; 1931.

is Richter, Geo. A., Ind. and Eng. Chem., vol. 23, No. 4, p. 371; 1931. 
No analyses of air within libraries were made, as a survey of library conditions recently completed ${ }^{16}$ showed that the acid constituents of the air are not generally removed. It was therefore assumed that the sulphur-dioxide content of air in the average library is practically the same as that of the outside air.

\section{DESCRIPTION OF APPARATUS}

A diagram showing the plan of the apparatus used is given in Figure 1. The cabinet, $A$, in which the exposure of the paper to the action of sulphur dioxide was made, was a double-walled box, fashioned of sheet metal and glass, the inside dimensions being 18 by 30 by 20 inches. Access to the interior was provided for by a circular door (18 inches in diameter) in the rear of the cabinet. This door

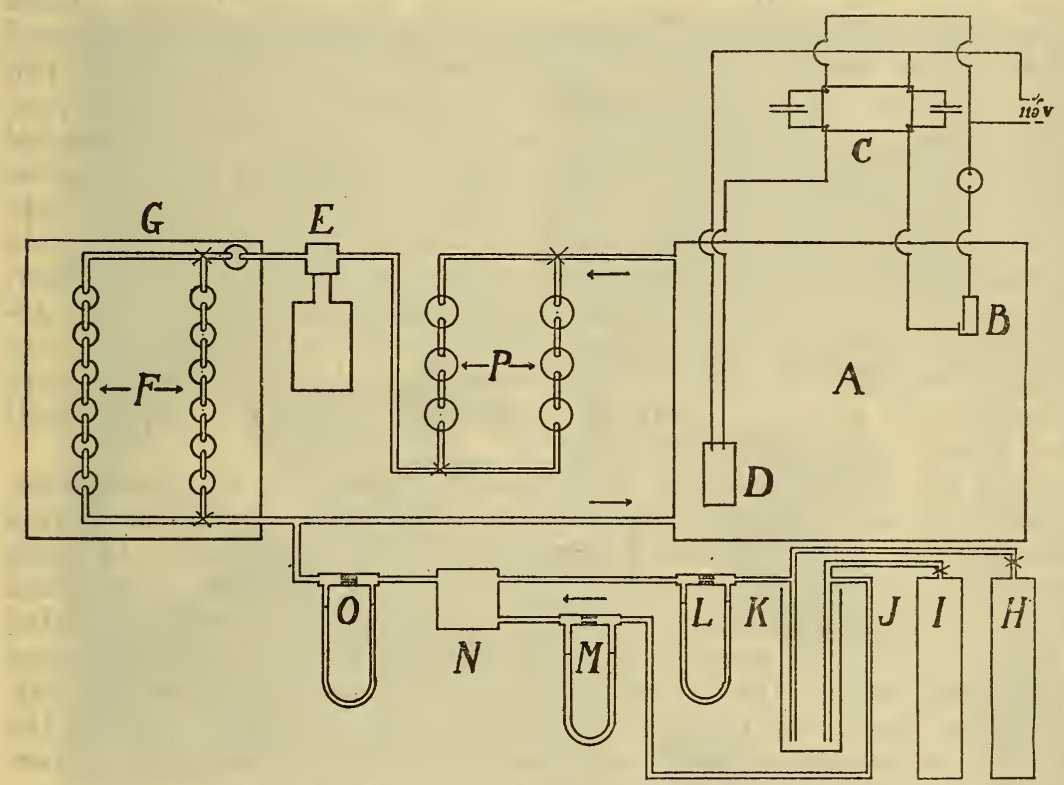

FIGURE 1.-Diagram of apparatus for exposure of paper to sulphur dioxide

was secured by clamps when the apparatus was in operation. In the front of the cabinet two armholes fitted with rubber gauntlets afforded a means of manipulating the specimens without disturbing conditions of temperature and humidity within the apparatus. ${ }^{17}$

Control of temperature was accomplished by means of a bimetallic strip, $B$, so adjusted that a slight decrease in temperature caused the strip to actuate a mercury relay, $C$, which in turn closed another circuit supplying current to a $600 \mathrm{w}$ open-coil heater, $D$, within the cabinet. The heat supplied then caused the bimetallic strip to break contact, thus automatically severing the heater circuit. Even distribution of heat throughout the cabinet was assured by the use of an electric fan. 
The air was withdrawn from the cabinet by means of a small motor-driven centrifugal pump, $E$, passed through a train of gaswashing bottles, $F$, containing an aqueous solution of glycerin (specific gravity 1.1813 at $25^{\circ}$ C.), and then returned to the cabinet. The humidity train was immersed in a water bath, $G$, held at the cabinet temperature to eliminate excessive heat losses and to aid in keeping the humidity as nearly constant as possible. The relative humidity was maintained constant to within \pm 1 per cent.

The mechanism used to introduce the sulphur dioxide into the cabinet consisted of a source of sulphur dioxide, $H$, and air, $I$, a safety valve for each gas, $J, K$, a differential valve for each gas, $L, M$, a mixing chamber, $N$, and a master differential valve, $O$, to govern release of the mixture into the cabinet itself. The sources of the sulphur dioxide and of air used were cylinders containing these gases, equipped with valves permitting fine adjustment. Each safety valve consisted of a $T$ with an elongated leg which was immersed in mineral oil, each of the valves being submerged to the same depth to insure equal pressure on each line. Variation of the oil level produced a corresponding variation in gas pressure. The differential valves, each consisting of a capillary tube connecting the two arms of an oil manometer and previously calibrated to determine the rate of flow, governed the relative quantities of air and sulphur dioxide entering a 2-liter glass bottle which served as the mixing chamber. The rate of flow of the pure air from $F$ having previously been determined by means of a gas meter, the mixture, the flow of which from $N$ was controlled by the valve, $O$, was released at such a rate as to form with the stream of pure air a mixture of from 2 to 9 parts sulphur dioxide per $1,000,000$.

After circulating through the cabinet containing the specimens, but before reaching the circulating pump, the residual sulphur dioxide was removed by passing the outcoming air from the cabinet through a series of gas-washing bottles, $P$, containing alkaline, saturated barium chloride solution to which phenolphthalein had been added as an indicator. As soon as one-half of the solution in the absorption train turned white, thus showing lowered efficiency as an absorbent, the entire train was replaced by a fresh one. Table 1 shows the variation of sulphur-dioxide content during five runs of 240 hours each. The apparatus is further illustrated by Figure 2.

TABLE 1.-Variation of sulphur-dioxide content of air in cabinet 1

\begin{tabular}{|c|c|c|c|c|c|}
\hline & Run No. & $\underset{2}{\text { Run No. }}$ & $\underset{3}{\operatorname{Run} \text { No. }}$ & $\underset{4}{\text { Run No. }}$ & $\underset{5}{\operatorname{Run} N o .}$ \\
\hline 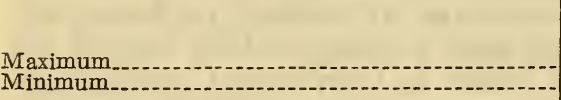 & $\begin{array}{r}\text { Parts per } \\
\text { million } \\
9.0 \\
3.0\end{array}$ & $\begin{array}{r}\text { Parts per } \\
\text { million } \\
9.2 \\
3.0\end{array}$ & $\begin{array}{r}\text { Parts per } \\
\text { million } \\
8.6 \\
2.6\end{array}$ & $\begin{array}{r}\text { Parts per } \\
\text { million } \\
8.7 \\
2.2\end{array}$ & $\begin{array}{r}\text { Parts per } \\
\text { million } \\
8.0 \\
4.6\end{array}$ \\
\hline Average 2 & 6.2 & 5.4 & 5.8 & 5.8 & 5.8 \\
\hline
\end{tabular}

1 Computed from control data.

2 Average of readings taken at hourly intervals. 
B. S. Journal of Research, RP407

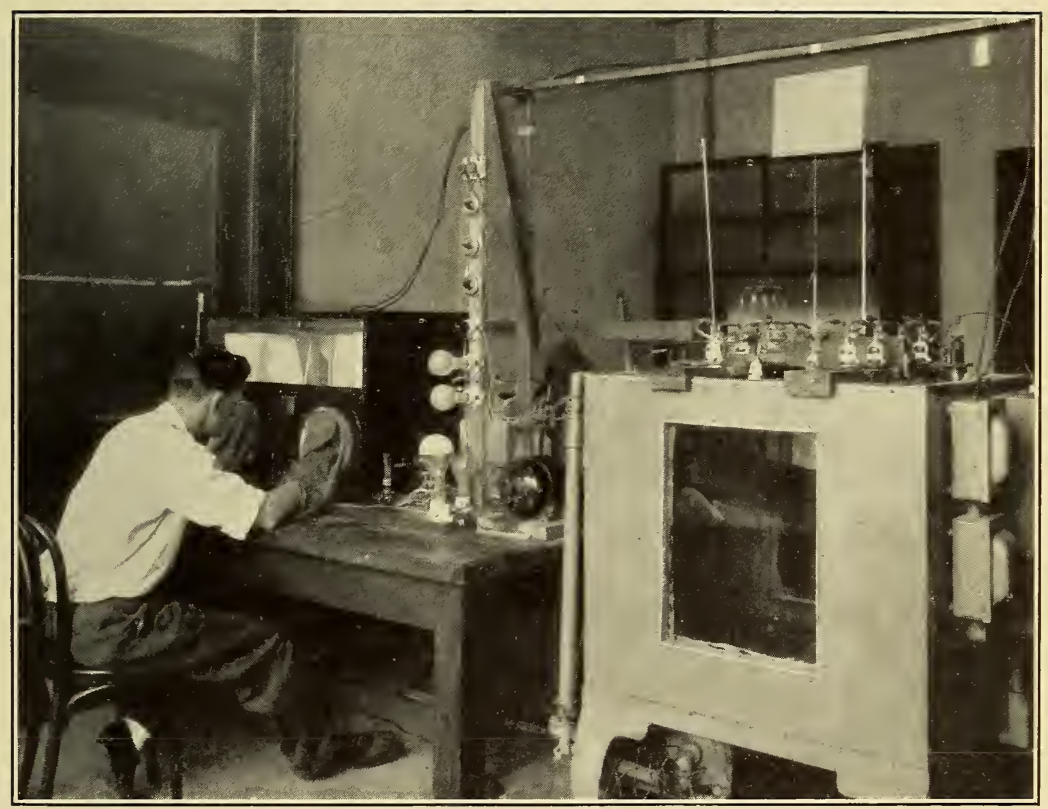

FigdRE 2.-Apparatus for exposing the paper to polluted air showing means of manipulating samples

Note rubber gauntlets allowing inclosed manipulation. 


\section{DESCRIPTION OF PAPERS USED}

The papers exposed to the action of sulphur dioxide were carefully chosen with the view of having them as representative of the current type of both printing and writing record papers as was possible with the necessarily limited number used. The characteristics of these papers are shown by the test data given in Table 2 . In those types generally having a wide range of quality, papers representative of the usual highest and lowest quality were included as far as possible. The properties considered most indicative of high quality in record papers are fiber purity, indicated by a high alpha cellulose content and a low copper number, minimum amounts of acid and rosin, and sufficient strength. In any consideration of strength it must be noted that writing papers are usually made stronger than book papers in order to withstand the greater stresses to which they are subjected. 


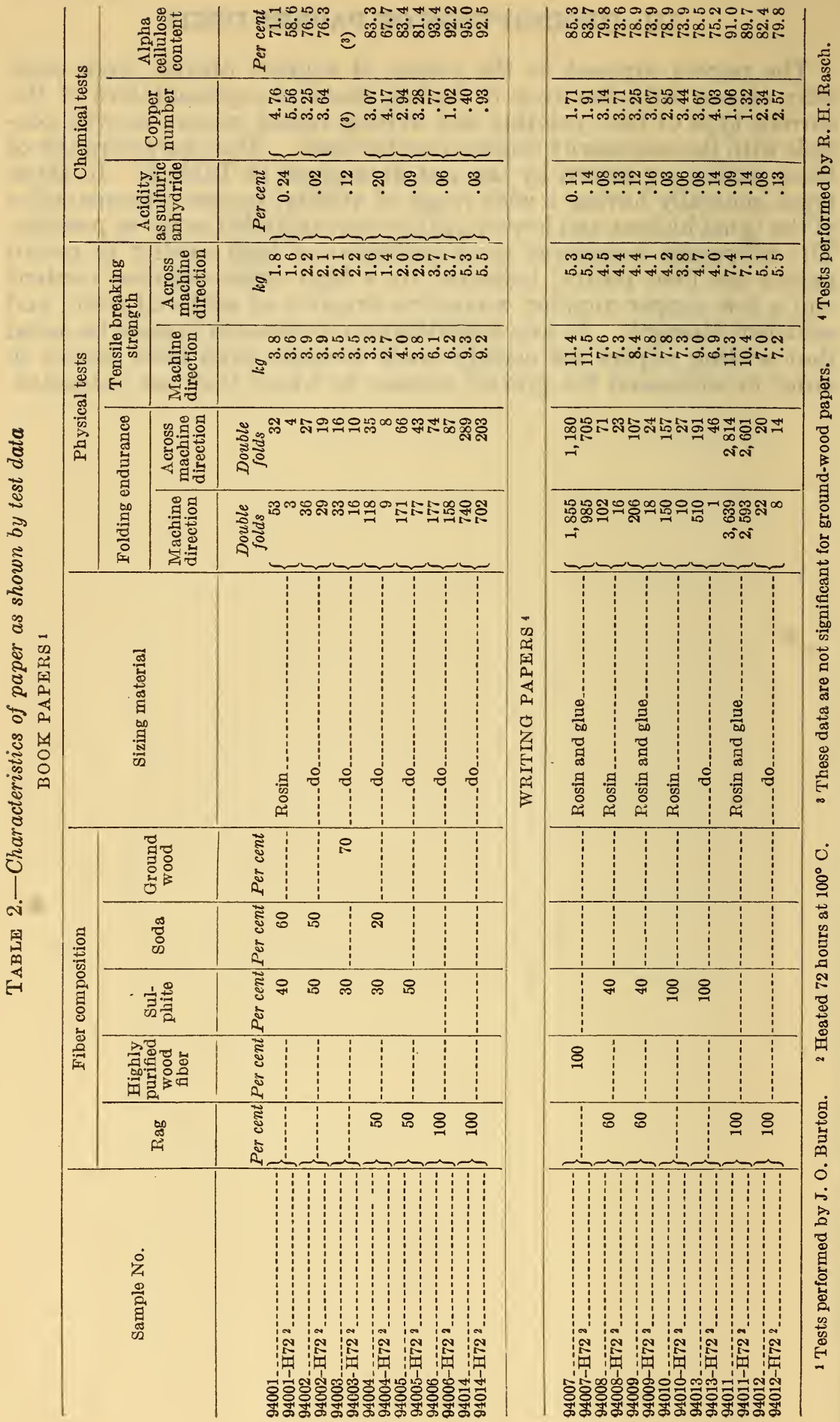




\section{DESCRIPTION OF TEST METHODS}

The test data for fiber composition, folding endurance, and tensile breaking strength given in Table 2 were obtained by the official methods of the Technical Association of the Pulp and Paper Industry. ${ }^{18}$ The folding endurance data given in Table 3 , however, were not obtained with a Schopper type of tester and a fixed initial tension of 1 kilogram, as specified in the association method, a M. I. T. type of folding endurance tester being used for these data, since it facilitates variation in the tensile stress. Such variation was desirable, as with a tension of $1 \mathrm{~kg}$. some of the book papers would not have a significant number of folds, while, on the other hand, unnecessary time would be consumed in testing some of the stronger writing papers. Folding data obtained with different tensions are not comparable, but this is immaterial where the percentage loss in folding endurance is the only required information. As an aid in determining the relative stability of the specimens to be treated, they were heated at $100^{\circ}$ C. $\left(212^{\circ} \mathrm{F}\right.$.) for 72 hours. Further details of this test and of its use in the classification of papers have been given in previous bureau publications..$^{19} 20$

The determination of alpha cellulose content and of copper number was made by modified procedures developed by the bureau specifically for testing paper, ${ }^{21}$ except that $1 / 4$-inch squares were substituted for ground specimens in order to eliminate any possible contamination of the treated samples through action of the acid on the metallic grinder. The alpha cellulose content of the cellulosic material is that part which is insoluble in a sodium hydroxide solution of mercerizing strength (17.5 per cent $\mathrm{NaOH}$ ) under certain specified conditions, and is regarded as a measure of the amount of unmodified cellulose which the material contains. The modified forms of cellulose possess the quality of reducing copper from alkaline copper solutions, and owing to their unstable nature are considered as deleterious impurities.

The determination of acidity was made as follows: A sample of air-dry paper cut into $y_{4}$-inch squares and weighing approximately $1 \mathrm{~g}$. was well mixed with $150 \mathrm{ml}$ of boiling distilled water in an Erlenmeyer flask. The resulting mixture was then heated to boiling and allowed to boil for one minute. After cooling to room temperature, the flask was swept out for 15 minutes with air free from carbon dioxide after which phenolphthalein was added and the mixture titrated with hundredth normal alkali to a faint pink color, persisting one minute. The sweep was kept in operation during the titration. The results were expressed as per cent sulphuric anhydride, being the number of milliliters of $0.01 N$ alkali times 0.04 divided by the weight in grams of the sample, dried to constant weight $\pm 10 \mathrm{mg}$ at $105^{\circ} \mathrm{C}$.

\footnotetext{
${ }^{18}$ Copies of the official paper-testing methods of the Technical Association of the Pulp and Paper Industry may be obtained from the secretary, at 370 Lexington Avenue, New York, N. Y.

${ }_{10}$ Rasch, R. H., A Study of Purified Wood Fibers as a Paper-Making Material, B. S. Jour. Research, vol. 3, p. 469; 1929 。

20 Burton, J. O., Permanence Studies of Current Book Papers, B. S. Jour. Research, vol. 7, p. $429 ; 1931$. ${ }^{21}$ Burton, J. O., and Rasch, R. H., The Determination of the Alpha Cellulose Content and Copper Number of Paper. B. S. Jour. Research, vol. 6, p. 603; 1931.
} 


\section{PROCEDURE}

Twenty sheets ( 8 by 10\% inches) of each paper to be tested were conditioned at 65 per cent relative humidity and $21^{\circ} \mathrm{C}$. $\left(70^{\circ} \mathrm{F}\right.$.) for 48 hours, after which they were removed to the test cabinet, where they were suspended and exposed as previously described. They were then removed from the cabinet and placed in a closed vessel, through which a stream of nitrogen at 65 per cent relative humidity was passed to eliminate any adhering sulphur dioxide. After washing in this manner for 24 hours, the sample was removed in a closed vessel to an air-conditioned testing chamber, maintained at 65 per cent relative humidity and $21^{\circ} \mathrm{C}$. $\left(70^{\circ} \mathrm{F}\right.$.), where strips for the determination of folding endurance and tensile strength were cut and tested as rapidly as possible. Untreated specimens of each paper were tested simultaneously with the treated specimens in order that the results might be strictly comparable. The decrease in folding endurance as shown in Table 3 was then computed. The remainder of the sample was cut into $1 / 4$-inch squares for use in determinations of moisture content, copper number, alpha cellulose content, and total acidity. Four papers were treated simultaneously in the cabinet.

\section{RESULTS}

The results of the experimental work are given in Table 3, which shows the physical and chemical changes induced by exposure to sulphur dioxide. It will be noted that in every case a marked decrease in folding endurance and an increase in acidity occurred. The color of the treated sheets was also affected, the specimens becoming dull gray.

Table 4 contains data showing the reproducibility of the effect of the exposure. Two series of independent tests were made on duplicate test specimens from five different papers. It should be noted that the data on folding endurance show the embrittling effect produced by each of two runs to be approximately the same. The experimental data on acidity and alpha cellulose content also agree very well, considering the nature of the material under examination. The copper numbers vary rather widely in all but one instance where excellent agreement was obtained. 


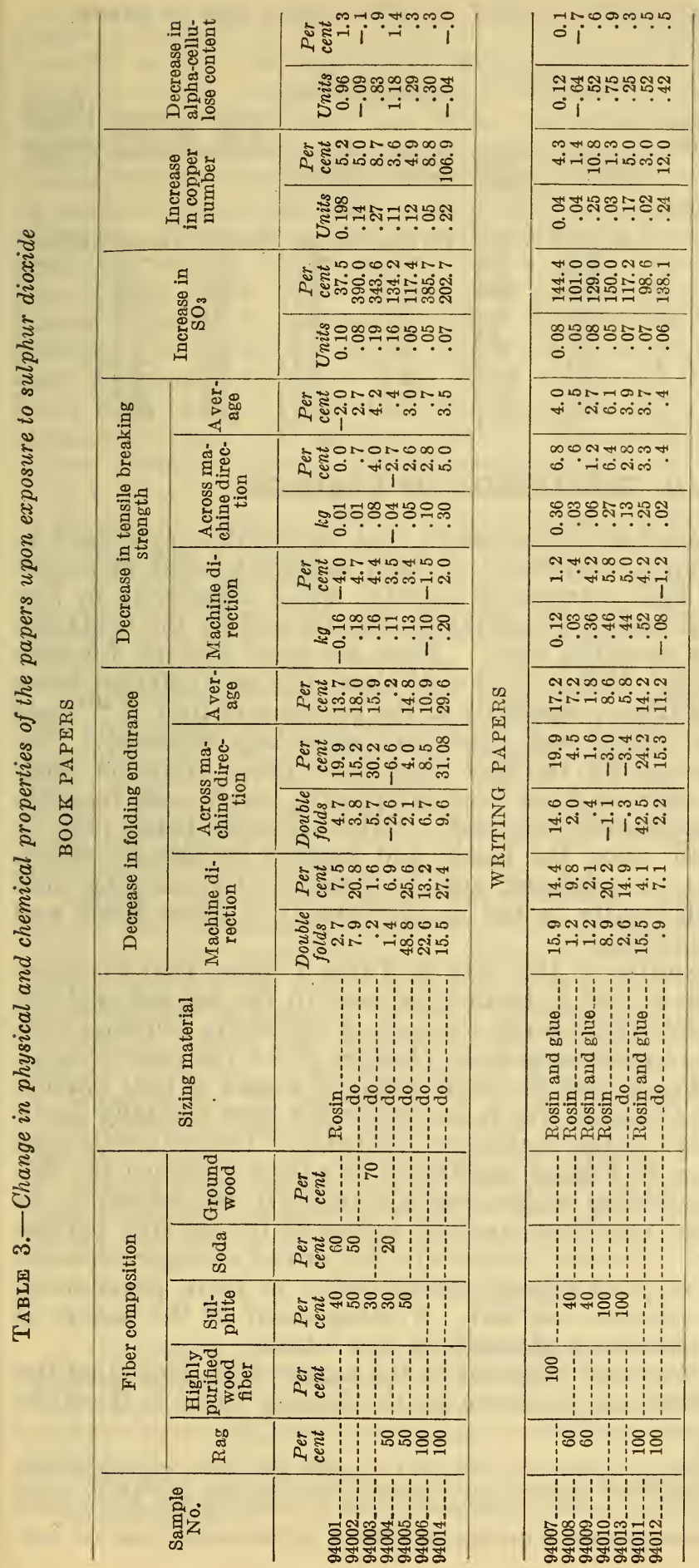


TABLE 4.-Reproducibility of effect of sulphur dioxide upon the papers

\begin{tabular}{|c|c|c|c|c|c|c|c|c|}
\hline \multirow{2}{*}{ Sample No. } & \multirow{2}{*}{$\begin{array}{l}\text { Run } \\
\text { No. }\end{array}$} & \multicolumn{2}{|c|}{$\begin{array}{l}\text { Loss of folding en- } \\
\text { durance }\end{array}$} & \multicolumn{2}{|c|}{$\begin{array}{l}\text { Loss of tensile } \\
\text { breaking strength }\end{array}$} & \multirow{2}{*}{$\begin{array}{l}\text { Increase } \\
\text { in per } \\
\text { cent SO 3 }\end{array}$} & \multirow{2}{*}{$\begin{array}{l}\text { Increase } \\
\text { in copper } \\
\text { number }\end{array}$} & \multirow{2}{*}{$\begin{array}{l}\text { Decrease } \\
\text { in alnha } \\
\text { cellulose } \\
\text { content }\end{array}$} \\
\hline & & $\begin{array}{l}\text { Machine } \\
\text { direction }\end{array}$ & $\begin{array}{l}\text { Across } \\
\text { machine } \\
\text { direction }\end{array}$ & $\begin{array}{l}\text { Machine } \\
\text { direction }\end{array}$ & $\begin{array}{l}\text { Across } \\
\text { machine } \\
\text { direction }\end{array}$ & & & \\
\hline 94002 & \multirow{6}{*}{$\begin{array}{l}4 \\
5 \\
4 \\
5 \\
3 \\
5 \\
3 \\
5 \\
4 \\
5\end{array}$} & \multirow{6}{*}{$\begin{array}{r}\text { Per cent } \\
20.0 \\
2.5 \\
-1.6 \\
4.9 \\
6.7 \\
2.2 \\
-3.4 \\
7.6 \\
27.7 \\
27.0\end{array}$} & \multirow{6}{*}{$\begin{array}{r}\text { Per cent } \\
14.2 \\
16.2 \\
26.0 \\
34.4 \\
9.5 \\
10.0 \\
4.2 \\
-1.1 \\
27.0 \\
36.7\end{array}$} & \multirow{6}{*}{$\begin{array}{r}\text { Per cent } \\
5.3 \\
.0 \\
1.4 \\
7.4 \\
-.5 \\
1.3 \\
1.9 \\
6.4 \\
-1.8 \\
5.8\end{array}$} & \multirow{6}{*}{$\begin{array}{r}\text { Per cent } \\
-1.4 \\
2.8 \\
6.1 \\
1.9 \\
1.8 \\
-.5 \\
2.6 \\
-. .2 \\
-11.5 \\
11.4\end{array}$} & \multirow{6}{*}{$\begin{array}{r}\text { Per cent } \\
450 \\
330 \\
373 \\
314 \\
90 \\
112 \\
132 \\
126 \\
100 \\
306\end{array}$} & \multirow{6}{*}{$\begin{array}{r}\text { Per cent } \\
-5.6 \\
5.0 \\
-12.1 \\
8.7 \\
1.5 \\
1.4 \\
-9.5 \\
10.8 \\
51.0 \\
162.8\end{array}$} & \multirow{6}{*}{$\begin{array}{r}\text { Per cent } \\
-1.4 \\
-.1 \\
.9 \\
.9 \\
-.6 \\
-.9 \\
.9 \\
.4 \\
.0 \\
.0\end{array}$} \\
\hline 94003 & & & & & & & & \\
\hline _94008 & & & & & & & & \\
\hline - & & & & & & & & \\
\hline $94014 \ldots$ & & & & & & & & \\
\hline & & & & & & & & \\
\hline
\end{tabular}

\section{DISCUSSION OF RESULTS}

The data contained in Table 3 show that the acidity (expressed as per cent of sulphuric anhydride) of each sample treated increased upon exposure. This increase in acidity, while significant in any event, is more so if caused by sulphuric acid formed by the oxidation of sulphur dioxide upon the sheet. There are good grounds for such an assumption, since Wilkie ${ }^{22}$ showed that such an oxidation takes place upon cotton fabric, especially in the presence of iron, ${ }^{23} 2425$ and since both cotton fabric and paper are essentially cellulose. The analogy is completed by the fact that most paper contains small amounts of iron derived from iron equipment, water, and reagents used in the paper-making processes. Sulphuric acid, being nonvolatile, would remain upon the paper and exert a continuous effect. Either sulphurous or sulphuric acid is capable of promoting acid hydrolysis, ${ }^{26}$ which results in the embrittlement of paper fibers and their eventual crumbling.

Further consideration of the data in Table 3 shows that exposure to sulphur dioxide caused a distinct increase in the copper number, accompanied by relatively small changes of the alpha cellulose content (that is, 7 of 14 specimens show changes of 0.3 per cent or less). This seems to indicate that the main point of attack is that portion of the material of the sheet which had originally been partially modified by "hydration" in the beaters or otherwise. The embrittlement shown by decrease in folding endurance is added evidence for this point of view, as folding endurance is commonly considered to be partially dependent on the cementing action of the gel-like portion of the paper fiber. It is not known whether or not a longer exposure to the action of sulphur dioxide would result in more pronounced changes of alpha celiulose content. Further study of the nature of the embrittling reactions is planned for the future.

On comparing the embrittlement of the papers with their qualities for permanent record use as shown by the data in Table 2 , it will be

22 See footnote 14, p. 160 .

23 Cooke, S. F., Rôle of Certain Metallic Ions as Oxidation Catalysts, J. Biol. Chem., vol. 10, p. $289 ; 1926$.

$2 \varepsilon$ Wilson, L. P., Catalytic Action in the Oxidation of Cellulose, J. Soc. Chem. Ind., vol. 39, p. 177 T: 1920.

${ }_{25}$ Baudisch, O., and Davidson, D., Catalytic Oxidation by Means of Complex Iron Salts, J. Biol. Chem., vol. 11, p. $50 ; 1927$.

${ }^{26}$ Heuser, West, and Esselen, Textbook of Cellulose Chemistry, p. 121, McGraw-Hill Book Co.; 1926. 
noted that there is no constant relation between their quality and their resistance to the action of sulphur dioxide. This may be readily seen in the case of the book papers by a comparison of the data in Tables 2 and 3 on papers Nos. 94003, 94004, and 94014. It will be noted that paper No. 94003, a low-grade paper containing 70 per cent ground wood, possessed low initial strength, which decreased considerably on artificial aging by heat. This specimen also suffered a marked decrease in folding endurance upon treatment with sulphur dioxide. Paper No. 94004, a medium-quality paper having an alpha cellulose content of 83 per cent and a copper number of 3.07 , failed completely under the heat test, but showed practically no change upon exposure to sulphur dioxide. The opposite was observed in sample No. 94014, having an alpha cellulose content of 95 per cent and a copper number of 0.40 , which withstood the heat test with very little change, but lost about 30 per cent of its folding endurance upon treatment with sulphur dioxide. The writing papers examined show a similar effect. For instance, sample No. 94009, having an alpha cellulose content of 78.9 per cent and a copper number of 3.25 , and sample No. 94013, with an alpha cellulose content of 78.5 per cent and a copper number of 3.67 , both low-grade papers, show low stability under the heat test, but are relatively unaffected by sulphur dioxide, while the opposite is true of No. 94007 (alpha cellulose content 85.3 per cent, copper number 1.71) and No. 94011 (alpha cellulose content 91.0 per cent, copper number 1.06). These findings show that even the best grades of the papers examined were not proof against the deteriorating action of air polluted with sulphur dioxide, thus corroborating the results obtained by Richter. ${ }^{27}$ In this connection it may be noted that in the case of Nos. 94008 and 94009, which are identical except for sizing, No. 94009, sized with rosin and glue, appears to be more resistant to sulphur dioxide. The difference is very slight, however.

Figures 3 and 4 compare the relative order of stability as established by per cent decrease in folding endurance after artificial aging by heat with the order established by change in folding endurance, acidity, and copper number after treatment with sulphur dioxide. It should be noted that in Figure 4 the order of stability as shown by resistance to heat is exactly the reverse of that obtained after treatment with sulphur dioxide. A similar tendency may be observed in Figure 3.

Regardless of the mechanism of the reactions and of relative resistance to sulphur dioxide, the mere fact that pronounced chemical and physical deterioration of paper may be produced by concentrations of sulphur dioxide approaching those actually encountered in urban communities in so short a period as 10 days indicates that measures to prevent acid pollution of the air in libraries are very necessary.

\section{SUMMARY}

1. Exposure of book and writing papers to air containing 2 to 9 parts of sulphur dioxide per $1,000,000$ for 240 hours at $30^{\circ} \mathrm{C}$. ( $\left(86^{\circ} \mathrm{F}\right.$.) and 65 per cent relative humidity resulted in embrittlement of the papers, as evidenced by decrease in folding endurance, usually of considerable magnitude.

27 See footnote 15, p. 160 . 


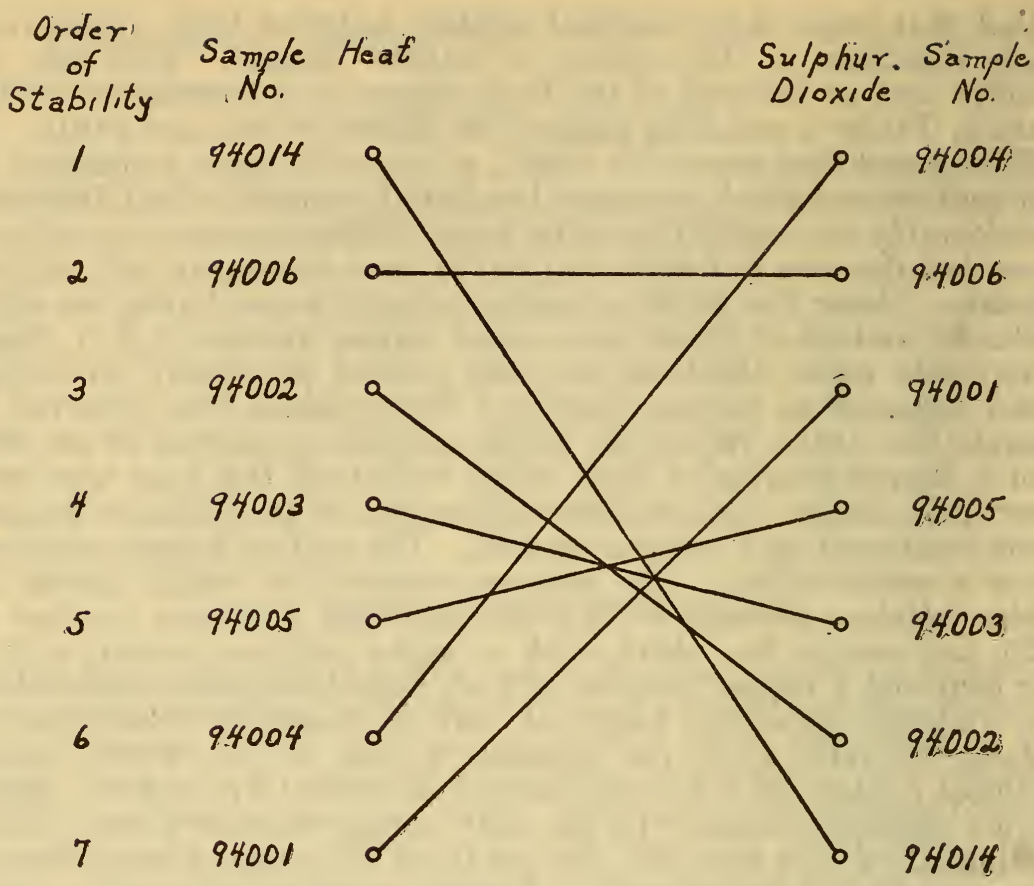

FIGURE 3.-Relative order of stability of book papers as established by decrease in folding endurance under heat and sulphur dioxide

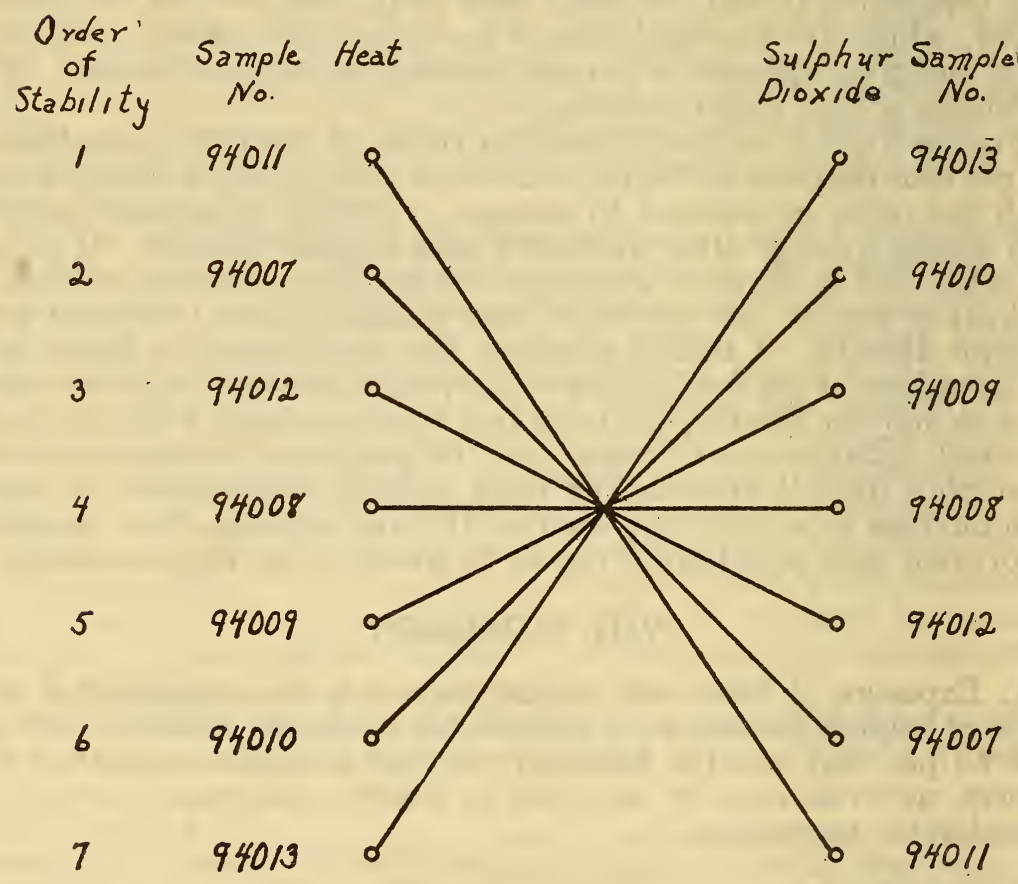

FIGURE 4.-Relative order of stability of writing papers as established by decrease in folding endurance under heat and sulphur dioxide 
2. The embrittlement of the papers was accompanied by large increases in acidity and significant increases in copper number, but with slight decreases in alpha cellulose content. The possibility that the hydrolyzed portions of the paper fibers were further hydrolyzed, causing a loosening of the cementing "gel" which is formed particularly in beating the fibers, is suggested.

3. The effects noted bore no constant relation to the initial quality of the papers; some of the lower-grade papers, unsuitable in other respects for permanent records, showed the greatest resistance to the action of sulphur dioxide.

4. While the results obtained are considered quite convincing direct evidence of the desirability of preventing acid pollution of library air, further study of the nature of the deteriorative reactions s planned.

\section{ACKNOWLEDGMENT}

The assistance of W. L. Iolt ${ }^{28}$ throughout this work is hereby gratefully acknowledged.

Washington, November 25, 1931.

${ }^{28}$ Assistant research associate, National Research Council. 